\title{
0 conhecimento de Geologia e Paleontologia como suporte no aprendizado de Geografia no Ensino Médio
}

The knowledge of Geology and Paleontology as a support for Geography learning in high school

\author{
Felipe Antônio Souza Penha ${ }^{1}$, Luciana Freitas de Oliveira França ${ }^{2}$, Marcia Evangelista Sousa ${ }^{3}$, Flaviana Jorge de Lima ${ }^{4}$ \\ 1 - Graduando em Geografia, Univ. Fed. Pernambuco. \\ 2 - Prof. Adjunta, Colegiado de Geografia, Univ. Fed. Pernambuco, ORCID ID http://orcid.org/0000-0002-2057-287X. \\ 3 - Profa. Geografia da Rede Municipal de Petrolina, Graduada em Geografia, Especialista em Ensino de Geografia e Mestre em Educação \\ 4 - Doutora em Geociências, Lab. Paleontologia, Depto. Ciências Biológicas. Univ. Regional do Cariri.

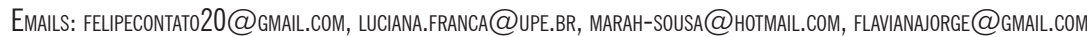

Abstract: This paper presents the experience of Geology and Paleontology study group (GEOMÉDI0) with twenty students from the first year of high school in the Reference School Dom Helder Câmara, municipality of Lagoa Grande, Pernambuco State. This group was created to minimize the distance of the contents related to Geology and Paleontology inserted in Geography, since in most cases these themes are not prioritized, either because of reduced hours or the absence of these disciplines during the formation of the Geography teacher. The students had theoretical and practical classes, which included field activities, production of scientific abstracts on the topics covered and the experience in the group and elaboration of models and other didactic materials. Thus, the experience of GEOMÉDIO proves the importance of teaching-learning activities beyond the classroom, awakening in students a greater interest in Geosciences. This action became necessary and multiplying as new classes will be inserted in GEOMÉDIO group with the same objective.

\section{Manuscrito:}

Recebido: 23/10/2018

Correção: 26/12/2018

Aceito: 21/01/2019

Citação: Penha, F. A. S., França, L. F. de 0., Sousa, M. E. , Lima, F. J. 2019. 0 conhecimento de Geologia e Paleontologia como suporte no aprendizado de Geografia no Ensino Médio. Terræ Didatica, 15, 1-11, e019015. doi: 10.20396/td.v15i0.8653660

Palavras-chave: ensino, grupo de estudo, paleontologia, geologia

\section{Introdução}

A abrangência das Ciências que compõem a Geografia é bastante diversificada, no entanto, algumas delas são trabalhadas de forma superficial em sala de aula (Alonço \& Boelter, 2016). Dentre estas, a Geologia e a Paleontologia merecem destaque, pois contribuem para uma melhor compreensão sobre a origem do Planeta Terra e suas modificações sofridas ao longo do tempo geológico e sobre a evolução da vida. Apesar da grande relevância, os conteúdos das referidas ciências acabam enfrentando certa resistência dentro das escolas. Essa resistência pode estar pautada na carga horária reduzida na disciplina da Geografia, que acaba priorizando outros conteúdos; ou ainda se esbarra com o modelo de ensino tradicional que está presente nas escolas brasileiras.

A Paleontologia, por sua vez, é trabalhada nas matérias de Geografia, Ciências e Biologia. Contudo, na disciplina de Geografia o conteúdo é bastante simplista, muitas vezes se reduzindo a um texto complementar do livro didático (Penha, 2017). Por outro lado, nas disciplinas de Ciências e/ou Biologia, a Paleontologia tem maior destaque, principalmente no conteúdo que trata sobre a evolução das espécies. Heirich, Matsumura, Myszyski-Junior, Serdoko \& Bosseti (2015, p.2) enumeram alguns motivos que estariam associados à carência da Paleontologia no ambiente escolar:

A carência de abordagem desta temática pelos professores pode ocorrer por diversos motivos, tais como: a deficiência do conteúdo nos livros didáticos; a complexidade do assunto; a ausência de materiais paradidáticos (livros de apoio e réplicas de fósseis) e a falta de conhecimento científico para responder aos questionamentos em sala de aula (Heirich et al., 2015, p. 2).

O ensino de Geologia e Paleontologia nas escolas compreende uma ferramenta vital de conhecimento, possibilitando ao aluno uma visão crítica e compreensiva daquilo que está a sua volta. 
Apesar da problemática, algumas ações extensivas podem melhorar a difusão e o ensino dessas duas áreas científicas. As ações de difusão do conhecimento geológico e paleontológico nas escolas são de extrema importância, seja pela relevância dessas áreas do conhecimento ou pela própria carência da temática dentro da escola. É importante se pensar em atividades na sala de aula, intervenções extraclasse, projetos pedagógicos interdisciplinares, que promovam e desenvolvam ferramentas didáticas para um maior entendimento sobre a Geologia e Paleontologia de determinados ambientes, sobretudo do próprio cotidiano do aluno.

A criação do grupo de estudo GEOMÉDIO, que significa Grupo de estudos de Geologia e Paleontologia do Ensino Médio, buscou promover ações pedagógicas para um maior conhecimento das Geociências, contextualizando, por exemplo, o estudo geológico do cotidiano dos alunos. Entre os propósitos desse projeto está a elaboração de materiais didáticos para as aulas de Geologia e Paleontologia; estimular os professores do Ensino Médio na prática de atividades associadas ao conhecimento geológico e reforçar a importância da relação escola e universidade na formação dos alunos. Assim, este trabalho tem como objetivo difundir o ensino da Geologia e da Paleontologia por meio da formação de grupos de estudos em escolas estaduais do Vale do São Francisco, tendo como base o patrimônio natural da Bacia Sedimentar do Araripe, possibilitando a compreensão da história geológica da Terra a alunos do Ensino Médio do sertão pernambucano. A região do Cariri é reconhecida pela presença de fósseis com excelente estado de preservação, o que a torna uma área de imenso valor geológico e paleontológico. Logo, a exposição do aporte teórico juntamente com a visita a essa área é uma importante ferramenta para o processo de ensino-aprendizagem dos alunos.

\section{As Geociências no Ensino Médio}

O ensino da Geologia no campo escolar inicia-se ainda no Ensino Fundamental. Nos livros, suas representações globais são o primeiro contato com as Geociências, porém, algumas problemáticas alinham-se com esse contato.

Vários temas dizem respeito às Geociências possibilitando o diálogo e participação da Geologia no ensino escolar. Entretanto, há dificuldades na divulgação de conhecimentos geológicos específicos já que trabalhos em escala local são geralmente desenvolvidos nos meios acadêmicos e os livros didáticos adotados nas escolas trabalham com exemplos e ilustrações geológicas mais globais que são importantes, mas nem sempre trazem a contribuição específica que o professor deseja ou necessita (Almeida, Araújo \& Mello 2015, p.2).

Resultante desse processo, o ensino da Geologia ligado à Geografia vivencia obstáculos no processo de ensino e aprendizagem. Para Almeida, Araújo \& Mello (2015), apesar dos empecilhos presentes no ensino das Geociências na graduação dos professores e incorreções em livros, a educação é contínua e seu aprimoramento ocorre a partir de uma construção coletiva ligada a pesquisa. Nota-se que as barreiras do ensino geológico e paleontológico nas escolas podem ser revertidas a partir de uma regionalização dos conteúdos didáticos, associado a uma maior divulgação de estudos geológicos das universidades para as escolas (Martello et al., 2014).

Associado ao conteúdo da Geologia, a Paleontologia é a ciência que estuda a história evolutiva da vida dentro do tempo geológico, a partir dos fósseis (restos) ou do registro de atividades dos organismos denominados de icnofósseis. Na escola, o ensino paleontológico também é inserido como conteúdo de Ciências no Ensino Fundamental ou na Biologia no Ensino Médio, sendo importante para o conhecimento e formação básica dos alunos.

A recente história da Paleontologia em nosso país ganha cada vez mais importância à medida que novas descobertas são feitas. Tal importância reside no fato de podermos conhecer a vida pretérita local, cuja história foi longa (em termos de tempo geológico), e buscar a compreensão dos motivos do seu desaparecimento (Izaguirry et al., 2013, p.4).

Trabalhar a Paleontologia na sala de aula ainda representa uma dificuldade devido à ausência de conhecimento por parte dos professores e a falta de metodologias. Para Alencar \& William (2011) o assunto sobre evolução é mais trabalhado no Ensino Médio e, por isso, sofre problemas para realizar aulas sobre este tema sem levantar polêmicas, como a teoria evolucionista em oposição a criacionista. Assim, surge a importância da abordagem da Paleontologia para auxiliar no entendimento da evolução dos seres em toda a educação básica. 


\section{Meios de divulgação das Geociências}

\section{Geoparques}

A criação de geoparques, que são áreas de grande riqueza geológica e paleontológica associadas a questões culturais daquela localidade, promoveram transformações econômicas, sociais e políticas na região ao qual está inserida, sendo considerado uma ferramenta inovadora de divulgação científica. Geoparques são territórios bem delimitados geograficamente que possuem estratégia de desenvolvimento sustentável para a conservação do patrimônio geológico (Brilha, 2005). Além disso, possuem lugares com características importantes para a Geologia, ensino e turismo, pois apresentam sítios geológicos e paleontológicos (geossítios) extremamente didáticos e atrativos para seus visitantes.

Segundo Brilha (2005), um geoparque promove o ensino e divulgação das Geociências, a partir da identificação de áreas para conservação que se tornam educativas e importantes para professores que frequentemente estão inseguros sobre as aulas de campo. Assim, torna-se compreensivo a extrema importância dos geoparques para a divulgação do ensino das Geociências e áreas afins, onde é possível ver na prática a teoria ensinada, desenvolvendo estrategicamente a curiosidade e conhecimento do aluno.

O desenvolvimento de estratégias de promoção educativa recorrendo ao patrimônio geológico da região, com a disponibilização de guias devidamente treinados e de recursos educativos apropriados, tem-se revelado como um fator essencial para incentivar os professores a promoverem aulas de campo com os seus alunos, de diversos graus de ensino, particularmente pré-universitário (BRILHA, 2005, p.29).

No Brasil, o Araripe Geopark Mundial da UNESCO é um dos geoparques da Rede Global, localizado no estado do Ceará, Nordeste do Brasil. Abrangendo uma área aproximada de $3.441 \mathrm{~km}^{2}$, este é o único geoparque brasileiro e conta com nove geossítios que guardam a história geológica de diferentes períodos da Terra, sendo uma rica ferramenta de ensino e divulgação.

A Geologia e Paleontologia no ensino básico são tradicionalmente vistas de maneira teórica, associado ao não uso da prática como meio de complemento para melhorar a aprendizagem. Esse modelo torna-se centralizado nas escolas. Por outro lado, atualmente, meios informais podem ser usados como ferramenta de aprendizagem revolucionária.

Com base na abordagem da educação não formal percebe-se que ela representa acima de tudo um processo educativo social, de construção e valorização do ser humano, do indivíduo e de suas responsabilidades como cidadão, sejam elas voltadas a sociedade como ao ambiente natural. Dentre as oportunidades que as atividades não formais poderão promover está a popularização das Geociências. A partir de planos e projetos de divulgação que envolva a sociedade é possível desenvolver a sensibilidade e curiosidade quanto ao meio natural, nesse caso especificamente, a geodiversidade e todos os elementos a ela associados (Guimarães, 2016, p.108).

Diante disso, podemos destacar as atividades realizadas pelo geoparques e museus. Segundo a UNESCO (2016), os geoparques da rede mundial seguem como requisito o desenvolvimento de atividades educativas para todas as faixas etárias, divulgando os aspectos geológicos através de "clubes de crianças", "dia do fóssil", de maneira formal ou informal também para adultos. No Brasil, alguns museus realizam projetos de inserção da Geociências, possibilitando a amplitude do conhecimento. $\mathrm{Na}$ maioria das vezes esses contatos ocorrem em parceiras com escolas, como por exemplo, as atividades realizadas pelo Geopark Araripe, no Ceará (Boas, Brilha \& Lima, 2013).

Os estudantes (máximo 10) do Ensino Médio de diferentes escolas da região seriam convidados a participar numa semana de coleta de fósseis. Durante o período de férias escolares, os jovens efetuariam trabalhos com fósseis nas lajes calcárias extraídas nas pedreiras da região. Fariam também uma primeira seleção e tratamento dos exemplares recolhidos, sob a orientação de um professor ou responsável pela atividade. Alguns dos fósseis encontrados pelos estudantes seriam doados às respectivas escolas, com a ficha técnica completa e identificação do aluno que o resgatou. Esta atividade deve decorrer sempre sob a supervisão do DNPM (Boas, Brilha \& Lima, 2013, p.163).

\section{Museus}

Outra ferramenta importante para a divulgação das Geociências, com ênfase na Paleontologia, são os museus que focam a história natural do planeta. 
Essas importantes galerias com ricos acervos paleontológicos, resultam em uma importante prática pedagógica que pode ser usado para difusão da ciência paleontológica.

Os museus, através de suas práticas como identificação, conservação, pesquisa e educação, difundem por meio de suas exposições e atividades educativas o conhecimento científico. Com o tempo, a proteção do Patrimônio Natural, educação ambiental e educação para a Cidadania tornaram-se assuntos em que também ocorrem nesses espaços museológicos (Vieira et al., 2007).

Segundo Vieira et al. (2007), antigos museus de história natural especializaram-se por área. Essa transformação ainda atual dos museus quebrou a percepção antiga de lugares para depósito de objetos, passando a serem lugares de aprendizagem ativa e divulgação científica. No Brasil há uma variedade de museus paleontológicos que apresentam uma grande quantidade de amostras de fósseis, sendo visitados diariamente.

Na região da Bacia do Araripe, a Universidade Regional do Cariri (URCA) e o Museu de Paleontologia Plácido Cidade Nuvens (MPPCN), em Santana do Cariri-CE, realizam uma importante ação não formal, o projeto "Jovens Paleontólogos", que proporciona a alunos da rede pública da região do Geopark Araripe, experiências e aprendizagens no campo paleontológico. Os estudantes realizam trabalhos nos geossítios, avaliando seus aspectos geológicos e paleontológicos; além da formação para atuarem como guias no referido Museu de Paleontologia (Boas, Brilha \& Lima, 2013).

É importante destacar ainda os museus interativos, como por exemplo, o Museu de Oceanografia da Universidade Federal Rural de Pernambuco, Unidade Acadêmica de Serra Talhada (MO-UAST). Em uma sala temática do referido museu procurou-se "ensinar aos visitantes a teoria da Tectônica de Placas, mediante o emprego de jogos físicos e virtuais" (Lima et al., 2014). Ações como esta podem melhorar a difusão e o ensino de Geologia e Paleontologia.

Diante disso é possível compreender a importância de meios que proporcionam a divulgação do ensino da Geologia, que se associado ao campo escolar tornar-se um importante viés de aprendizagem. De forma lúdica e prática, museus e geoparques promovem importantes ações educativas.

Além dos museus e geoparques é importante citar as tecnologias digitais nas ações não formais ligadas ao ensino e divulgação da Paleontologia.
Um exemplo desse conteúdo digital é o canal e site, denominado "Colecionadores de Ossos", que está hospedado na rede mundial de computadores. $\mathrm{O}$ conteúdo produzido e divulgado pela mídia digital torna-se mais acessível à divulgação e uso no ensino das Geociências.

\section{Materiais e Métodos}

O objeto de estudo para este trabalho foi um grupo de vinte alunos do $1^{\circ}$ Ano do Ensino Médio da Escola de Referência Dom Helder Câmara, localizada no distrito de Vermelhos, a $22 \mathrm{~km}$ da Sede do município de Lagoa Grande-PE, que pertence à rede estadual e a rede integral de ensino do Estado de Pernambuco.

Na primeira etapa do trabalho foram levantadas as principais referências bibliográficas relacionadas à temática do ensino de Geologia e Paleontologia de caráter global e local, com ênfase na Bacia do Araripe, além de referências relacionadas aos aspectos geológicos, imagens de satélites e materiais didáticos associados às Geociências.

A segunda etapa correspondeu a um primeiro levantamento do conteúdo com os professores, no qual foi identificado que o $1^{\circ}$ Ano do Ensino Médio apresentava a temática associada à Geografia Física, com foco em Geologia. Posteriormente, foram planejados os dias e os horários que as aulas deveriam ocorrer na escola.

$\mathrm{Na}$ terceira etapa, elaborou-se o projeto de difusão da ciência geológica e paleontológica no Ensino Médio (Projeto GEOMÉDIO) que foi desenvolvido a partir da delimitação dos objetivos, conteúdo programático, quantidade de alunos participantes, horário das aulas, atividades de campo e avaliativas, além da produção de resumos científicos e elaboração de maquetes. O projeto foi então apresentado à direção escolar para sua avaliação.

$\mathrm{Na}$ quarta etapa, após a aprovação do projeto pela direção da escola, este foi apresentado aos alunos para que pudessem realizar a inscrição. Os alunos que apresentavam maiores dificuldades no aprendizado relacionado às Geociências foram selecionados pela professora responsável por lecionar a matéria de Geografia, das turmas do $1^{\circ}$ ano. O grupo de estudo teve duração de seis meses (março a setembro de 2017) com aulas teóricas e práticas. As aulas de Geologia e Paleontologia na escola foram realizadas com auxílio de equipamentos de apoio como projetor e computador, além do auxílio de imagens de satélite.

\begin{tabular}{c|c|c|c|c|c|}
\hline (C) Terrae Didat. & Campinas, SP & v.15 & $1-11$ & $\mathrm{e} 019015$ & 2019 \\
\hline
\end{tabular}


Na quinta etapa foram estudadas a Bacia e a Chapada do Araripe. Foram discutidas as estruturas geológicas das bacias sedimentares, estratigrafia e ocorrências no Brasil, com destaque para a Geologia e Paleontologia da Bacia do Araripe. Já sobre a Chapada do Araripe foram apresentadas as feições geomorfológicas. A parte teórica foi finalizada com as orientações da prática de campo ao Geopark Araripe, incluindo explicações para o preenchimento da ficha de campo.

\section{Resultados e discussões}

As ações não formais de ensino e aprendizagem ocorrem como complemento essencial do conteúdo escolar. Sendo assim, essa adição enriquece o conhecimento pautado em visitas aos museus, geoparques e mais recentemente ao uso dos conteúdos digitais, que crescem de forma significativa no Brasil. Assim, a seguir, destacam-se os resultados e discussões das ações formais e não formais desenvolvidos com o grupo de alunos.

\section{I - Formação do grupo de estudo}

Após os primeiros passos de iniciação do projeto, foi estimado junto com a professora de Geografia um quantitativo de alunos que apresentavam dificuldade de aprendizagem nos conteúdos de Geografia Física associadas aos aspectos geológicos. Foram selecionados 20 alunos pertencentes a quatro turmas do $1^{\circ}$ ano, sendo elas A, B, C e D.

$\mathrm{Na}$ primeira reunião com os alunos foi apresentado o que seriam trabalhados durante as aulas e como se daria o processo de ensino, os dias e horários. As aulas ficaram definidas com duração de cerca de 60 minutos, em um período de seis meses.

Ficou decidido no primeiro encontro que o grupo de estudos se chamaria Grupo de Estudo de Geologia e Paleontologia no Ensino Médio- GEOMÉDIO, a partir de uma sugestão dos alunos. Também foram apresentados aos alunos os conteúdos programáticos e as regras de boa convivência entre os membros, perpetuando o respeito entre todos, além do compromisso de aprendizagem. Assim, foi oficializada a criação desta ação escolar para a adição de conhecimento e aprendizagem.

\section{II - Aulas de Geologia e Paleontologia na escola}

As temáticas das aulas apresentadas podem ser vistas no quadro 1. A escolha dos conteúdos foi baseada em assuntos que são trabalhados na educação básica, adicionados ao contexto geológico e paleontológico regional.

A primeira aula foi a de introdução à Geologia e Paleontologia, onde foram explicados os significados dos termos geológicos, os campos da Geologia e seu objeto de estudo (Fig.1).

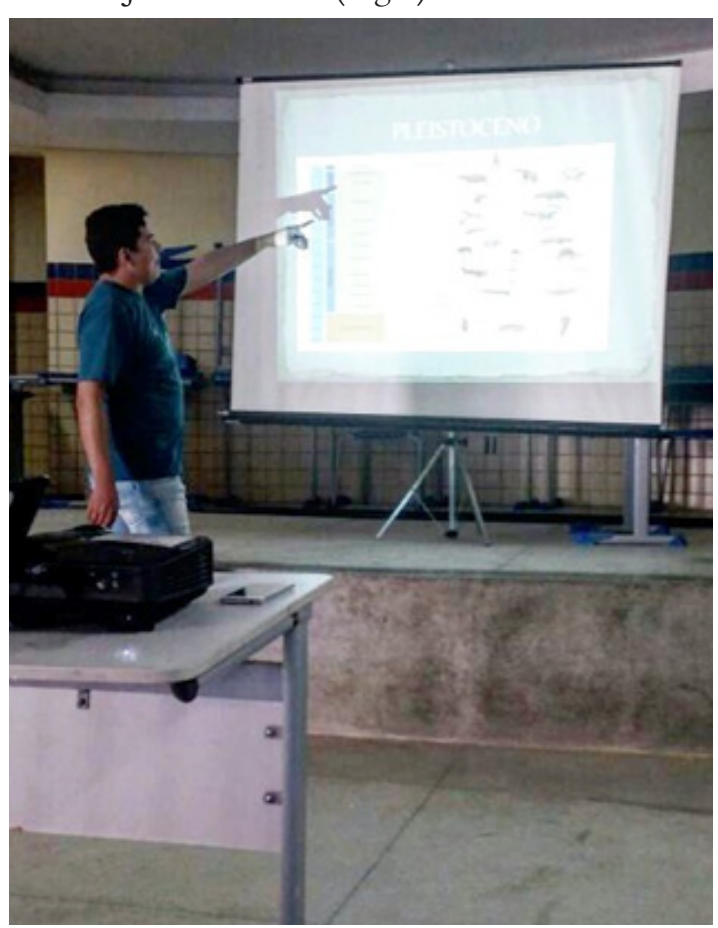

Figura 1: Aula de Introdução à Geologia e Paleontologia 
Também foi trabalhada a temática da estrutura interna da Terra. Foram apresentadas a divisão geoquímica e geodinâmica da Terra, e as ciências que auxiliaram nessa divisão, como por exemplo, a Geofísica, através da sismologia, gravimetria, paleomagnetismo, entre outras áreas do conhecimento.

Após a discussão da estrutura interna foi tratada a teoria da tectônica de placas, destacando as principais evidências científicas que justificam tal teoria. Foram explicados os principais limites de placas e suas principais consequências na formação do relevo terrestre. Foi possível compreender o processo geológico de transformação dos continentes, que ao longo de milhares de anos estiveram em constante movimentação, ocorrendo até hoje. Como exemplo principal para este conteúdo foi utilizado o processo de formação do Oceano Atlântico e como ocorreu a separação entre os continentes Sul Americano e Africano.

$\mathrm{Na}$ aula sobre os tipos de rochas foi explicado o processo de formação destas e a caracterização dos três tipos, ígnea, metamórfica e sedimentar. A partir deste entendimento foi possível compreender o que são rochas e minerais. Como complemento prático da aula, os alunos visitaram um afloramento de biotita xisto na localidade de Vermelhos, podendo regionalizar e contextualizar as características geológicas da região de onde residem (Fig. 2).

$\mathrm{Na}$ aula seguinte, abordou-se o tema depósito sedimentar e estratigrafia, destacando os tipos de depósitos e suas ocorrências. Novamente é exemplificado, de forma contextualizada, o transporte e deposição de sedimentos feita pelo Rio São Francisco em suas margens. Já na aula sobre estratigrafia, foi mostrado como ocorre às deposições em camadas e como cada camada pertence a uma unidade

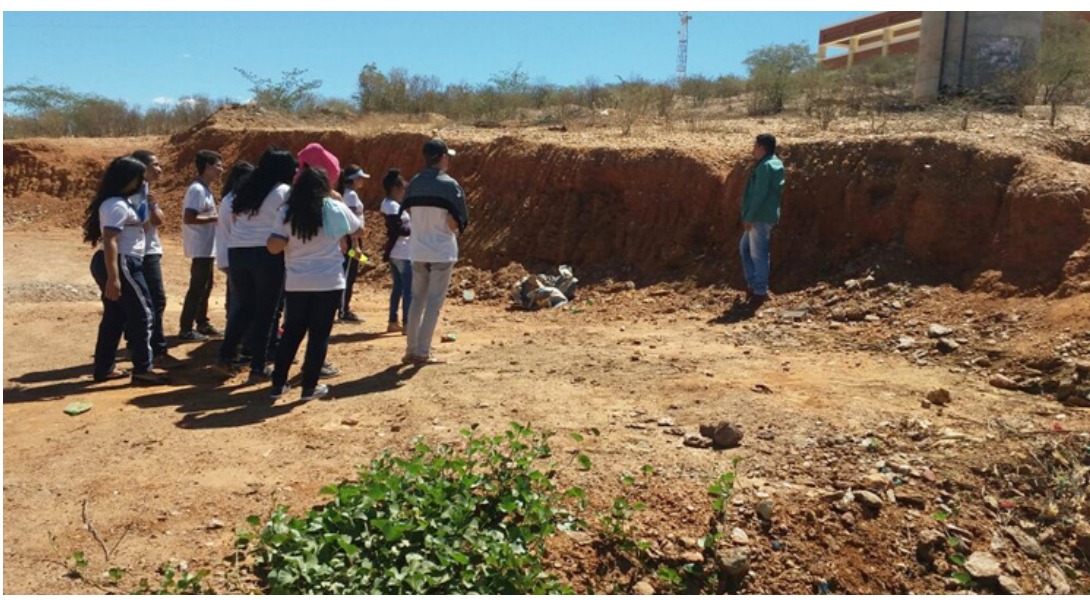

Figura 2. Visita ao afloramento de biotita xisto no povoado de Vermelhos, Lagoa Grande-PE temporal diferente. Foram ainda discutidos os tipos de datação que são feitas para identificar a idade de cada camada depositada.

$\mathrm{Na}$ aula de Paleontologia foi explicada sua diferença com a Arqueologia, pois costumam ser usadas como sinônimos equivocadamente. Foram repassados os conceitos de fóssil e tipos de fósseis, como ocorre o processo de fossilização e os principais grupos fósseis encontrados no Brasil, particularmente os da região Nordeste, com destaque para o patrimônio paleontológico da Bacia do Araripe. Para esta aula foram exibidas imagens de fósseis, esquemas dos processos de fossilização e algumas amostras de fósseis da Bacia do Araripe.

\section{III - Aula de campo no Geopark Araripe}

Entre os dias 7 e 9 de setembro de 2017, os alunos do grupo de estudo, juntamente com os estudantes de Geografia (membros do Grupo de Estudo Geodiversidade de Pernambuco da UPE Petrolina) realizaram uma viagem de campo de caráter extensionista ao Geopark Araripe, localizada na parte sul do Estado do Ceará. A ação prática teve como objetivo a difusão do ensino da Geologia e do patrimônio paleontológico da Bacia do Araripe, por meio do potencial geodidático da região.

A aula de campo foi realizada em três dos nove geossítios do Geopark Araripe. Optou-se por esse planejamento devido ao pouco tempo de estadia na região e pela distância significativa entre os geossítios. Em cada geossítio foram observadas e explicadas as características geológicas, o que proporcionou aos alunos, dentre outros aspectos, informações sobre: a estratigrafia da Bacia do Araripe, os processos tectônicos que influenciaram a região do Araripe, a formação das rochas sedimentares e, principalmente, o conteúdo fossilífero. Como ferramenta de análise e compreensão das características fisiográficas, foi usada uma ficha de campo elaborada por Sousa (2017), na qual várias informações foram questionadas, como a paisagem, Geologia, Geomorfologia, acessibilidade dos geossítios e sua potencialidade, por exemplo. 


\section{Geossítio Pontal da Santa Cruz}

Foi o primeiro geossítio visitado e está localizado no município de Santana do Cariri-CE, e corresponde aos arenitos da unidade geológica denominada Formação Exu. Neste ponto, apresentaram-se as informações geológicas do geossítio, além da história cultural do local com auxílio de um guia. O encontro foi realizado dentro da capela que está localizada no geossítio (Fig. 3) e que está associada a lendas e histórias populares ligadas à religiosidade local.

Além das características geográficas da região, foi explicada a importância dos arenitos, sua formação e sua característica de funcionar como uma "esponja", ao absorver a água das chuvas e distribuí-la pelas nascentes localizadas nas encostas da Chapada do Araripe. Assim, foi possível compreender as características geológicas e estratigráficas da área, que foi a última unidade geológica da Bacia do Araripe a se depositar. Também foi possível identificar a Geomorfologia da Chapada do Araripe.

A partir das observações inseridas na ficha de campo, observou-se que este geossítio possui um alto nível dificuldade de acesso, médio potencial didático e risco de degradação relacionada às práticas turísticas.

\section{Geossítio Ponte de Pedra}

Localizado no município de Nova Olinda-CE, Ponte de Pedra foi o segundo geossítio visitado, e que também corresponde a rochas da Formação Exu. Neste local, abordou-se a importância histórica do geossítio, pois a estrutura natural servia de passagem para os antigos povos que habitavam a região.

A partir das observações de Ponte de Pedra (Fig. 4), foi possível identificar feições erosivas no solo e o tipo de vegetação presente, com enclaves de cerrado, totalmente diferentes da vegetação de caatinga presente nas regiões de menor altitude. Diante disso, foi possível compreender o diferencial da vegetação e os fatores como altitude, hidrologia e precipitação influenciando na configuração da paisagem e em sua modificação.

Como medida de conservação da estrutura geológica de Ponte de Pedra, é permitida apenas a passagem de duas pessoas por vez. Foi possível relacionar ações ligadas a geoconservação e os impactos ambientais que poderiam ser gerados pela reforma da rodovia CE-292, aproveitando-se para informar sobre projetos de restauração da ponte com intuito

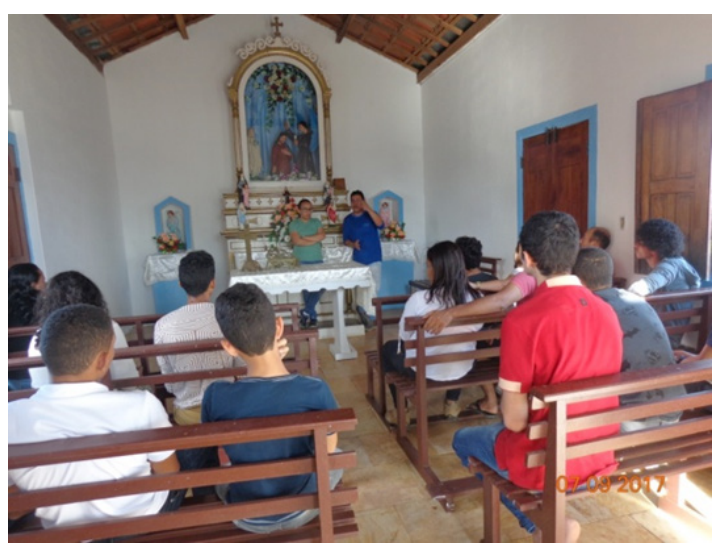

Figura 3 Momento de explicação sobre os aspectos geológicos e históricos do Geossítio Pontal da Santa Cruz na capela local

de evitar desmoronamento. Também foi possível identificar a fauna e flora presentes.

A partir da ficha de campo foram registradas as informações sobre tipos de rochas, geomorfologia, aspectos físicos e sociais, geoconservação e acessibilidade ao geossítio. Na segunda visita, o conhecimento geológico e geográfico dos alunos tornou-se mais apurado, já que é possível a identificação dessas características através de um olhar crítico e perceptível. O potencial didático foi classificado como médio, a acessibilidade com alto nível de dificuldade devido à declividade do terreno, risco de queda e de insolação. Além disso, o geossítio apresenta alto risco de degradação pelos processos erosivos e obras de engenharia.

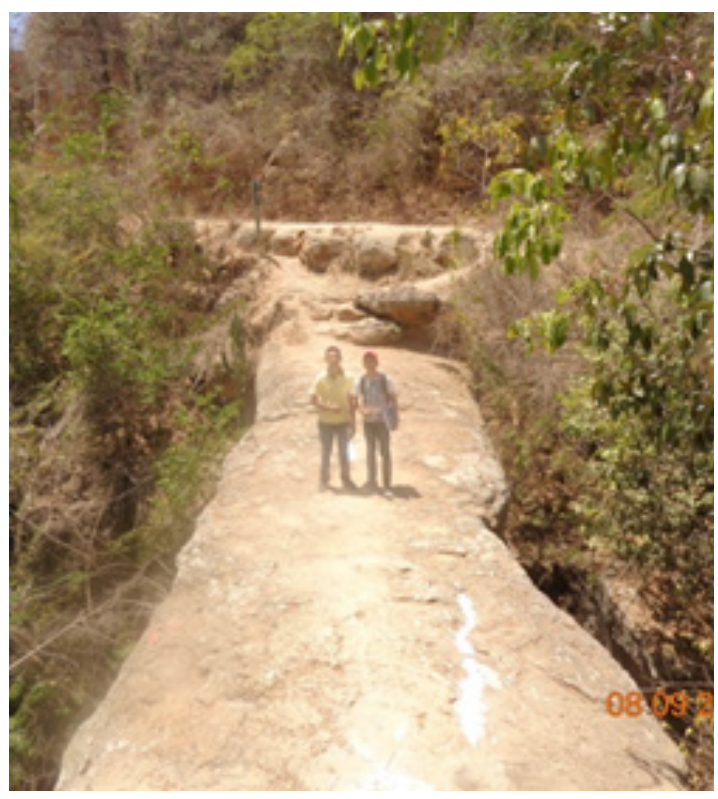

Figura 4. Geossítio Ponte de Pedra 

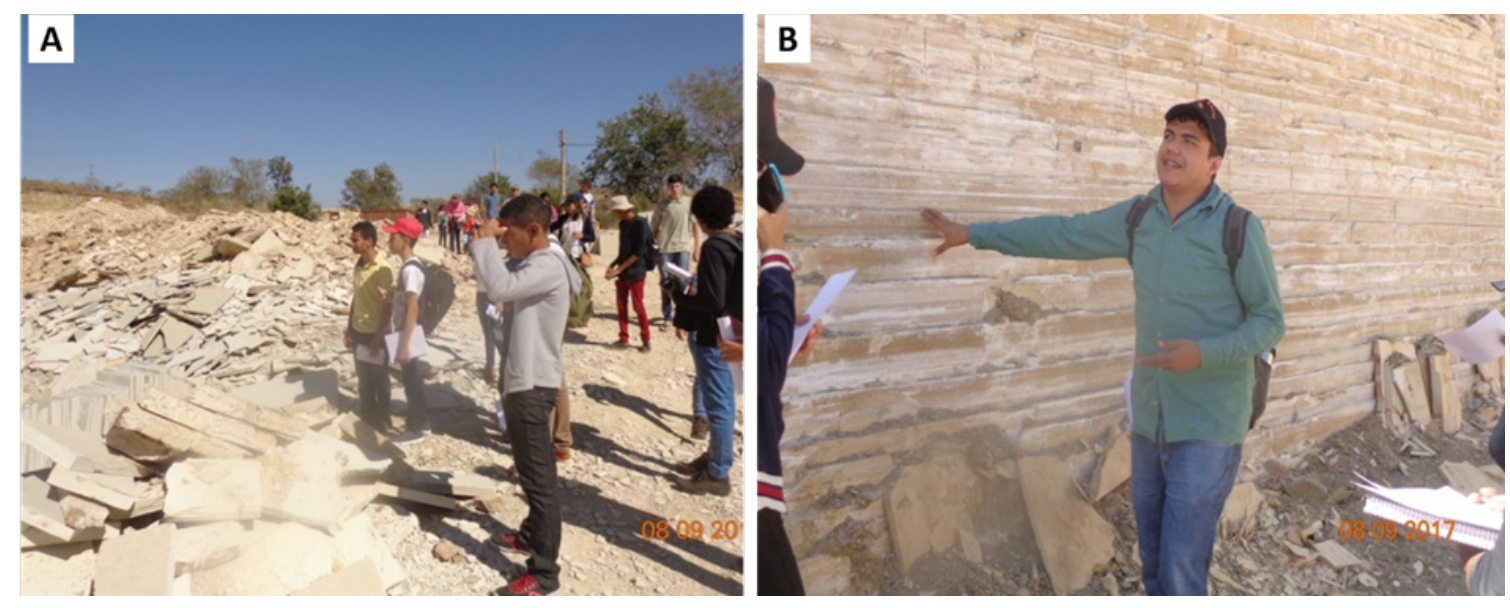

Figura 5. Geossítio Pedra Cariri: (A) Alunos observando os rejeitos de mineração de calcário laminado. (B) Explicação sobre a formação geológica do calcário laminado.

Em junho de 2018 a "visitação ao geossítio Ponte de Pedra foi proibida, devido ao alto risco de desabamento do geossítio, corroborando com o resultado da avaliação referente ao risco de degradação" (PENHA \& FRANÇA, 2018, p.8). Em setembro de 2018, a Ponte de Pedra foi recuperada através de uma obra de contenção. No entanto, ficou descaracterizado com sua configuração original, comprometendo seu valor estético.

\section{Geossítio Pedra Cariri}

O terceiro e último geossítio visitado foi o Geossítio Pedra Cariri (Fig. 5), localizado às margens da rodovia de acesso ao município de Nova Olinda-CE. O geossítio está presente em uma área de mineração de calcário laminado usado na construção civil. Vale lembrar que a área de visitação desse geossítio não corresponde ao local de exploração da rocha.

A área de exploração da Pedra Cariri é um dos mais importantes sítios geológicos do Geopark Araripe. A partir do primeiro contato foi possível visualizar os afloramentos de calcário laminado que são extraídos a todo instante. As escavações possibilitaram um corte preciso nas camadas, deixando-as totalmente expostos, sendo possível identificar informações geológicas, mineralógicas e estratigráficas.

Durante o campo, foram passadas várias informações acerca de características geológicas do geossítio. O patrimônio paleontológico também foi apresentado aos alunos, que por sua vez foram questionados sobre qual tipo de ambiente de sedimentação levou à formação daquelas rochas, fazendo com que os alunos associassem o tipo de deposição com o ambiente que ali existiu há milhares de anos.

Diante das informações explicadas, foi possível compreender as características geológicas e paleontológicas do geossítio, que é um dos principais depósitos de fósseis no mundo e possui grande importância para o Geopark Araripe, pois centenas de fósseis foram e são encontrados no local. A atividade mineradora próxima ao geossítio propiciou aos alunos vários achados fossilíferos, no entanto, tal atividade também leva a perda de material (Fig. 6). A partir desse momento surgiu um debate entre os alunos sobre a conservação do patrimônio paleontológico e como poderia ser feita.

A partir da ficha de campo, os alunos classificaram o potencial didático como alto, pois o geossítios possui ricos elementos da geodiversidade. A acessibilidade do local foi classificada como de baixo grau de dificuldade pelos alunos, justificado pela facilidade de acesso. Quanto ao risco de degradação foi considerado alto, principalmente por conta da mineração.

Dentre os geossítios visitados, o Geossítio Pedra Cariri apresentou uma das melhores experiências no aspecto paleontológico, devido sua riqueza fossilífera e de como esse geossítio é vulnerável. Assim, foram introduzido os conceitos sobre geoconservação e a legislação quanto à preservação dos fósseis. Os alunos questionaram sobre a conservação desses locais associada aos riscos de degradação dos fósseis.

\section{Museu de Paleontologia Plácido Cidades Nuvens}

Como complemento final da aula de campo, os alunos visitaram o Museu de Paleontologia Plácido Cidades Nuvens, em Santana do Cariri-CE. 

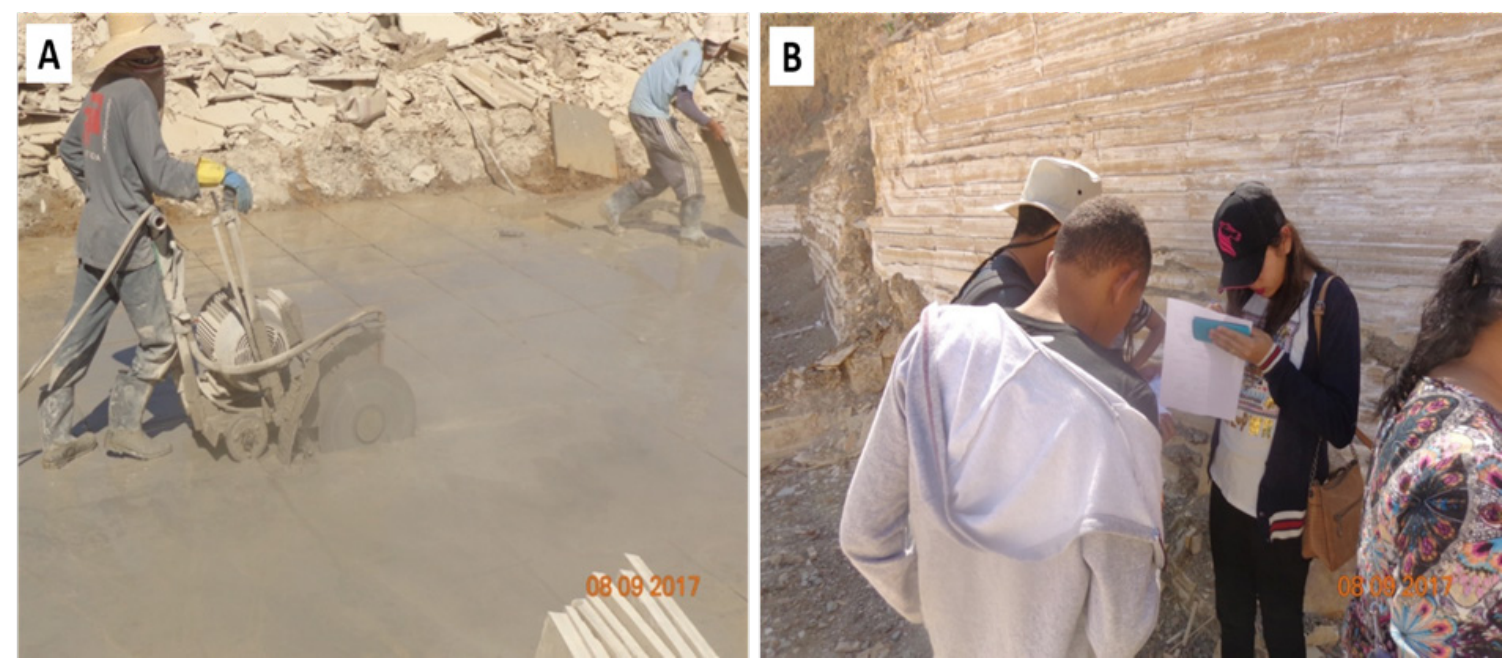

Figura 6. (A) Processo de retirada das placas de calcário pelos mineradores; (B) Coleta de informações sobre o geossítio

Neste local, os estudantes tiveram a oportunidade de vivenciar a experiência de conhecer um museu paleontológico pela primeira vez, sendo assim, um momento de realização e mais conhecimento, vivenciados nos dias que estiveram visitando o Geopark Araripe (Fig.7).

Os fósseis do museu estão expostos em diferentes posições e galerias, no qual correspondem a cada formação geológica da Bacia do Araripe, e os espécimes do Grupo Santana compõem a maior parte do acervo. Os alunos demonstraram curiosidade diante do perfeito estado de conservação dos espécimes, como por exemplo, os peixes da Formação Romualdo (maioria tridimensionais) e as plantas e insetos da Formação Crato (completamente preservados).

Adicionalmente à visita, os alunos visitaram o local onde são guardados os fósseis do museu que não estão em exposição. O local abriga além dos fósseis recém-chegados das escavações, fósseis em estudo, material tipo e holótipos. $\mathrm{Na}$ ocasião, os alunos puderam ver novos fósseis que não estavam expostos e puderam aprender sobre todos os processos pelos quais os fósseis passam até chegar à exposição, desde a preparação até a identificação.

\section{IV - Finalização das atividades na escola}

Como conclusão das atividades foi realizada uma roda de debates sobre o que foi analisado nas fichas de campo. Este momento foi de compartilhamento das informações que foram levantadas pelos alunos, relatos das experiências vividas no campo e quais questões que chamaram mais atenção durante as visitas.
$\mathrm{Na}$ escola, os resultados foram amplamente perceptíveis, pois além de compartilhar com os colegas de sala os aprendizados, relatos e experiências, os alunos ampliaram os conhecimentos associados às disciplinas de Geografia e Biologia, principalmente nos quesitos relacionados à Geologia e Paleontologia, como os tipos de rochas e fósseis. Como ferramenta de divulgação na escola, os estudantes confeccionaram uma réplica da maquete da Bacia do Araripe, vista no Museu de Paleontologia Plácido Cidade Nuvens. A maquete (Fig. 8) foi usada nas apresentações de trabalhos de Geografia para exemplificar o tema bacia sedimentar, além de ser exposta na feira ciências da escola. Utilizando da maquete, os alunos explicaram toda a formação da Bacia do Araripe, destacando as formações sedimentares e os principais conteúdos fossilíferos, expandindo o conhecimento adquirido para toda a escola.

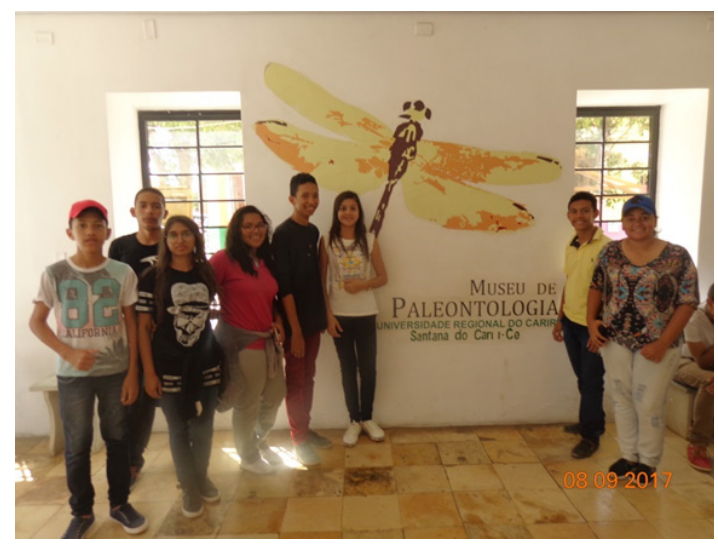

Figura 7. Alunos do GEOMÉDIO visitando o Museu de Paleontologia Plácido Cidades Nuvens, em Santana do Cariri-CE 
Diante disso é possível compreender a importância de meios que proporcionam a divulgação do ensino da Geologia, que se associado ao campo escolar tornar-se um importante viés de aprendizagem. De forma lúdica e prática, museus e geoparques promovem importantes ações educativas.

\section{Considerações Finais}

A Geologia e a Paleontologia são ferramentas essenciais para a aprendizagem de conteúdos da Geografia Física, como: tectônica de placas, estrutura interna da Terra, rochas, minerais, relevo, paleoambiente, entre outras temáticas. No entanto, nas escolas, esses conhecimentos são abordados de forma superficial, com dados gerais sobre o sistema Terra, sem uma contextualização com as paisagens naturais aos quais os alunos estão inseridos. Assim, práticas pedagógicas como essa são importantes para que mudem a realidade dos alunos. Como uma prática está a inserção de grupos de estudos no Ensino Médio, com foco nessas temáticas, como o GEOMÉDIO, proposto na região de Lagoa Grande, no Estado de Pernambuco.

O GEOMÉDIO promoveu discussões sobre os principais temas da Geologia e Paleontologia, além de realizar aulas de campo na própria região onde está inserida a Escola de Referência Dom Helder Câmara. Também foi realizada uma expedição ao Geopark Araripe para conhecer três geossítios: Pontal da Santa Cruz, Ponte de Pedra e Pedra Cariri, além do Museu de Paleontologia de Santana do Cariri. Esses geossítios foram avaliados pelos alunos que consideraram, através das suas observações, o Geossítio Pedra Cariri o de maior potencial pedagógico e o Geossítio Ponte de Pedra com maior risco de degradação.

Os sítios paleontológicos e geológicos, especialmente as áreas de geoparques, são de extrema importância para o ensino, pois permite a avaliação in locu dos processos geológicos que ocorreram há milhares de anos e que hoje se encontram registrados nas rochas. Já o uso do patrimônio paleontológico e geológico da Bacia do Araripe vem como uma importante ação e ferramenta pedagógica. Uma das mais importantes regiões do mundo no campo das Geociências, o Geopark Araripe, é um verdadeiro laboratório a céu aberto, podendo ser utilizado pelos professores para uma melhor aprendizagem do conteúdo geológico/paleontológico e para maior interesse das ciências por parte dos estudantes.

A experiência vivenciada com o GEOMÉDIO

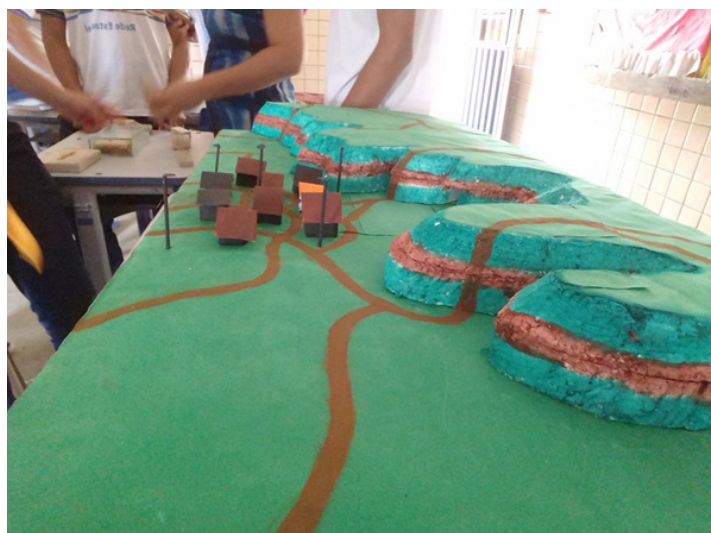

Figura 8. Réplica da Bacia Sedimentar do Araripe feita pelos alunos do GEOMÉDIO

comprova a importância das ações de ensino-aprendizagem além da sala de aula. Ações não formais possibilitam maior compreensão pelos discentes e quebram possíveis tradicionalismos no ensino, que levam muitas vezes ao desinteresse dos alunos pelas disciplinas. $\mathrm{O}$ aprendizado que foi possibilitado aos alunos do grupo tornou-se ação multiplicadora do interesse pelas ciências, já que a proposta do GEOMÉDIO permanecerá na escola, por sugestão da direção, e possibilitará novas aprendizagens com novos grupos de alunos.

O trabalho não apenas constitui ação de divulgação da Geologia e da Paleontologia, mas também possibilita o diálogo do aluno com conhecimentos científicos que o leva a refletir, questionar e se interessar por conteúdos, até então, distantes de sua realidade, como foi mencionado por um dos alunos. A ação pode ser vivenciada em qualquer instituição de ensino, possibilitando a compreensão do espaço geográfico, da história e evolução da Terra, da vida e das transformações contínuas que vivemos.

Atualmente o projeto foi expandido para duas escolas de referência do Município de Petrolina Doutor Pacífico Rodrigues da Luz e Marechal Antônio Alves filho para um total de 70 alunos, utilizando a mesma metodologia do GEOMÉDIO. Outras escolas de Petrolina já mostraram interesse para implantação do grupo de estudo nos próximos anos.

\section{Referências}

Alencar, E., \& William R. (2011). A importância do ensino de Paleontologia e Evolução. Maiêutica, 1(1), 27-29.

Almeida, C.N., Araújo C., \& Mello E.F. (2015). Geologia nas Escolas de Ensino Básico: a experiência do 
Departamento de Geologia da Universidade Federal do Rio de Janeiro. Terre Didatica, 11(3), 150-161. doi: http://dx.doi.org/10.20396/td.v11i3.8643643.

Alonço, M., \& Boelter, R. A. (2016). Paleontologia nos livros didáticos de biologia do Ensino Médio. In: VI Enebio e VIII Erebio Regional 3. (pp. 7672-7682). Maringá, Brasil.

Boas, M. V., Brilha, J. B. R., Lima, F. F. (2013). Conservação do patrimônio paleontológico do Geopark Araripe (Brasil): enquadramento, estratégias e condicionantes. Boletim Paranaense de Geociências, 70(2013), 156-165. doi: http://dx.doi.org/10.5380/ geo.v70i0.31418.

Brilha, J. B. R. (2005). Patrimônio Geológico e Geoconservação: a conservação da natureza na sua vertente geológica. Braga, Portugal: Palimage.

Guimarães, T. O. (2016). Patrimônio geológico e estratégias de geoconservação: popularização das Geociências $e$ desenvolvimento territorial sustentável para o litoral sul de Pernambuco (Brasil). Universidade Federal de Pernambuco, Brasil. (Tese de doutorado). Retirado de: https://repositorio.ufpe.br/handle/123456789/21931

Heirich, C. M., Matsumura, W. M. K., Myszyski-Junior, L. J., Serdoko, D., \& Bosseti, E. P. O. (2015). Aprendizado da Paleontologia no Ensino Básico da cidade de Tibagi, PR. Paleo PR/SC, Paraná, Brasil. Retirado de: http://www.fecilcam.br/paleoprsc/ data/uploads/o-aprendizado-da-paleontologia-no-ensino-basico-da-cidade-de-tibagi-n-pr.pdf.

Izaguirry, B. B. D., Ziemann, D. R., Muller, R. T., Dockborn, J., Pivotto, O. L., Costa, F. M., Alves, B. S., Ilba, A. L. R., Stefenon, V. M., \& Silva, S. D. (2013). A paleontologia na escola: uma proposta lúdica e pedagógica em escolas do município de São Gabriel, RS. São Carlos, Cadernos da Pedagogia. 7(13), 2-16.

Lima, M. M. M., Marques, P. C. F., Nunes, H. A. A, Cavalcanti, E. H. F., \& Silva-Cavalcanti, J. S. (2014). Proposta inovadora na aprendizagem da teoria da Tectônica de Placas no Museu de Oceanografia de Serra Talhada, Pernambuco. Terre Didati- ca 10(2), 140-150. doi: https://doi.org/10.20396/ td.v10i2.863737.

Martello, A. R., Novais T., Oleques L. C., Leal L. A., \& Rosa, Á. A. S. da. (2015). Uma experiência de inserção da paleontologia no ensino fundamental em diferentes regiões do Brasil. Terre Didatica, 11(1), 33-41. doi: https://doi.org/10.20396/ td.v11i1.8637308.

Penha, F. A. S. (2017). Difusão do Ensino de Geologia a partir da Interpretação dos Conceitos Geológicos e do Patrimônio Paleontológico da Bacia Sedimentar do Araripe (Trabalho de Conclusão de curso). Universidade de Pernambuco Campus Petrolina, Brasil.

Penha, F. A. S., \& França, L. F. O. (2018). Expedição ao Geopark do Araripe: discussão geocientífica feita pelos alunos do Ensino Médio sobre potencial pedagógico dos geossítios do Araripe. Petrolina, Brasil. III Encontro de Geografia do Vale do São Francisco (Sociedade/ Natureza/Trabalho em tempos de crises). Retirado de: https://gpvasfupe.wixsite.com/gpvasf/anais-eletronicos.

Severino, A. J. (2011). Metodologia do Trabalho Científico (23 ed.). São Paulo: Cortez.

Sousa, M. E. (2017). Avaliação do potencial pedagógico das paisagens naturais de Petrolina, Pernambuco (Dissertação de Mestrado). Universidade de Pernambuco Campus Petrolina, Brasil.

UNESCO, The United Nations Educational, Scientific and Cultural Organization, (2016). UNESCO Global Geoparks: celebrating earth heritage, sustaining local communities. Place de Fontenoy, France. Retirado de: http://unesdoc.unesco.org/ images/0024/002436/243650e.pdf.

Vieira, A. C. M., Novaes, M. G. L., Matos, J. S., Faria, A. C. G., Machado, D. M .C., \& Ponciano, L. C. M. O. (2007). A Contribuição dos Museus para a Institucionalização e Difusão da Paleontologia. Anuário do Instituto de Geociências UFRJ, 30, 158167. 